\title{
FACTORS INFLUENCING THE SEEDLING ESTABLISHMENT OF ENGELMANN SPRUCE AND SUBALPINE FIR
}

\author{
A. K. Knapp \\ W. K. Smith \\ Department of Botany \\ University of Wyoming
}

\section{Objectives}

Prescribed burning in U.S. National Parks has been employed as a substitute for natural fires to achieve vegetation and/or wildlife management objectives (Habeck 1970). One specific management objective in Glacier National Park (GNP) is the restoration of plant community diversity to pre-fire-suppression levels.

Following a fire (natural or prescribed), numerous site and environmental factors may be altered which can influence individual species success at the site and ultimately, the resulting plant community. A few of the factors known to be altered by burning are soil temperatures, water relations and erosion, atmospheric humidity and nutrient availability (Ahlgren and Ahlgren 1960; Sweeney and Biswell 1961; Smith and James 1977).

In the summer of 1981 , stand characteristics of a proposed prescribed burn site in GNP were evaluated, however, weather and site conditions were not adequate for burning during this season. Thus, a project was completed comparing the influence of two site and environmental factors usually altered by burning ( 1 itter depth and solar radiation) on the understory seedling establishment of Engelmann spruce (Picea engelmanii) and subalpine fir (Abies lasiocarpa). Factors influencing seedling establishment and success following a fire need to be evaluated before the successful prediction of plant reestablishment after prescribed burning can be accomplished. Fire characteristics resulting from a prescribed burn can then be manipulated to achieve management goals by altering specific site or environmental factors necessary for regenerating the desired plant community.

\section{Methods}

Seedlings of subalpine fir are generally more abundant in the subalpine forest understory than Engelmann spruce seedlings (Oosting and Reed 1952; Day 1972) and two factors commonly cited as influencing the differential establishment of these two conifers in the understory were evaluated. These factors are (1) reduced shade tolerance in Engelmann spruce compared to subalpine fir (Day 1972; Alexander 1974) and (2) greater root 
penetration in subalpine fir than Engelmann spruce which may increase establishment success of subalpine fir on the thick, rapidly drying litter layer characteristic of the subalpine understory (Oosting and Reed 1952; Smith and Clark 1960). Solar radiation was evaluated as a factor influencing seedling abundance in a southeast Wyoming subalpine understory by randomly selecting 70 seedlings of each conifer and measuring the total daily solar radiation received by each seedling to determine if seedlings occurred in understory locations that received different quantities of radiation. Additionally, the photosynthetic response of Engelmann spruce and subalpine fir to low incident solar radiation was compared for 2-4 yr-old seedlings in natural understory locations. Solar radiation was measured with a light meter (Lambda Instruments LI-185A) and a quantum sensor (LI-190S) and photosynthes is was measured with an open flow infrared gas analyzer (Beckman model 865).

To evaluate differences in seedling root penetration between the two conifers and its potential effect on differential seedling establishment, seedlings of both species were grown from seed collected from Colorado and Wyoming in a greenhouse environment similar to the understory and root length (penetration) were measured weekly for 10 weeks. Additionally, litter depth (organic matter above mineral soil) was measured at each understory seedling location.

Finally, the proposed Polebridge burn site in GNP was sampled for conifer density, basal area and frequency using the point-quarter distance method of Cottam and Curtis (1956).

\section{Results}

A comparison of the understory locations of subalpine fir and Engelmann spruce indicated that there was no minimum threshold of total daily solar radiation below which subalpine fir was present but Engelmann spruce was not, thus, solar radiation did not appear to be the factor responsible for the lower abundance of Engelmann spruce seedlings in the understory compared to subalpine fir. Photosynthesis in subalpine fir did appear to be better adapted for the shaded conditions of the understory compared to Engelmann spruce due to the lower quantity of solar radiation required for light saturation of photosynthesis and the greater photosynthetic rates at low levels of radiation in subalpine fir (Fig. 1).

Root growth and penetration was significantly greater in subalpine fir seedlings compared to Engelmann spruce seedlings, both initially (subalpine fir roots were $20 \mathrm{~mm}$ longer at $2 \mathrm{wks}$ ) and at the conclusion of the study (subalpine fir roots were $35.1 \mathrm{~mm}$ longer at 10 wks). Seedlings of Engelmann spruce were more common in understory locations of reduced litter depth compared to subalpine fir and both species were common on decayed wood (Fig. 2).

The stand characteristics for the Polebridge site in GNP are listed in Table 1 and indicate that Pseudotsuga menziesi $i$ was the dominant conifer 


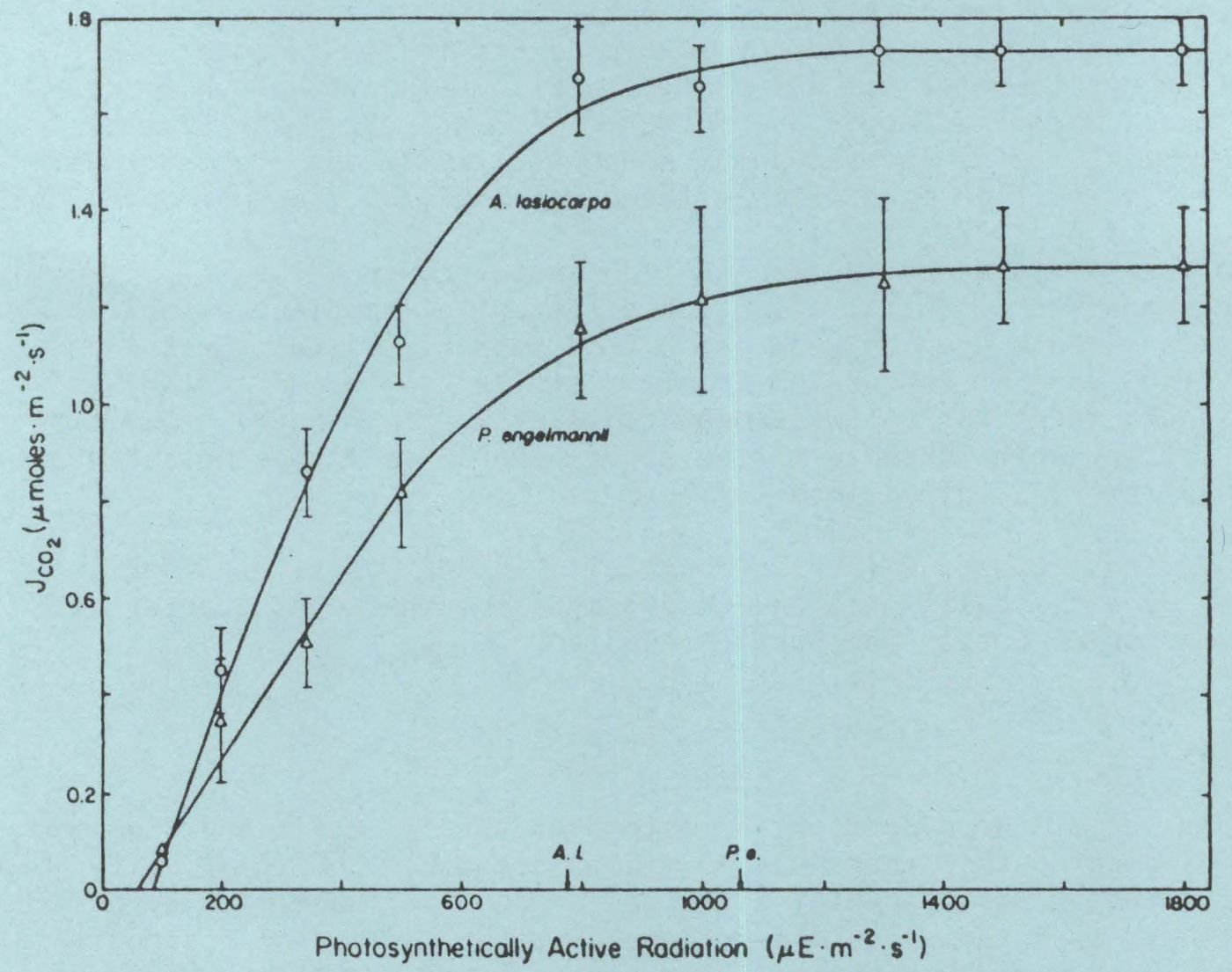

Figure 1. Response of net photosynthesis $\left(\mathrm{J}_{\mathrm{CO}_{2}}\right)$ to incident photosynthetically active radiation in seedlings of $\mathrm{A}$. lasiocarpa and $P$. engelmannil. Light saturation of photosynthesis (95\% maximum $\left.\mathrm{J}_{\mathrm{CO}_{2}}\right)$ Is Indicated for each conifer by arrows and vertical bars represent 1 standard error of the mean. 


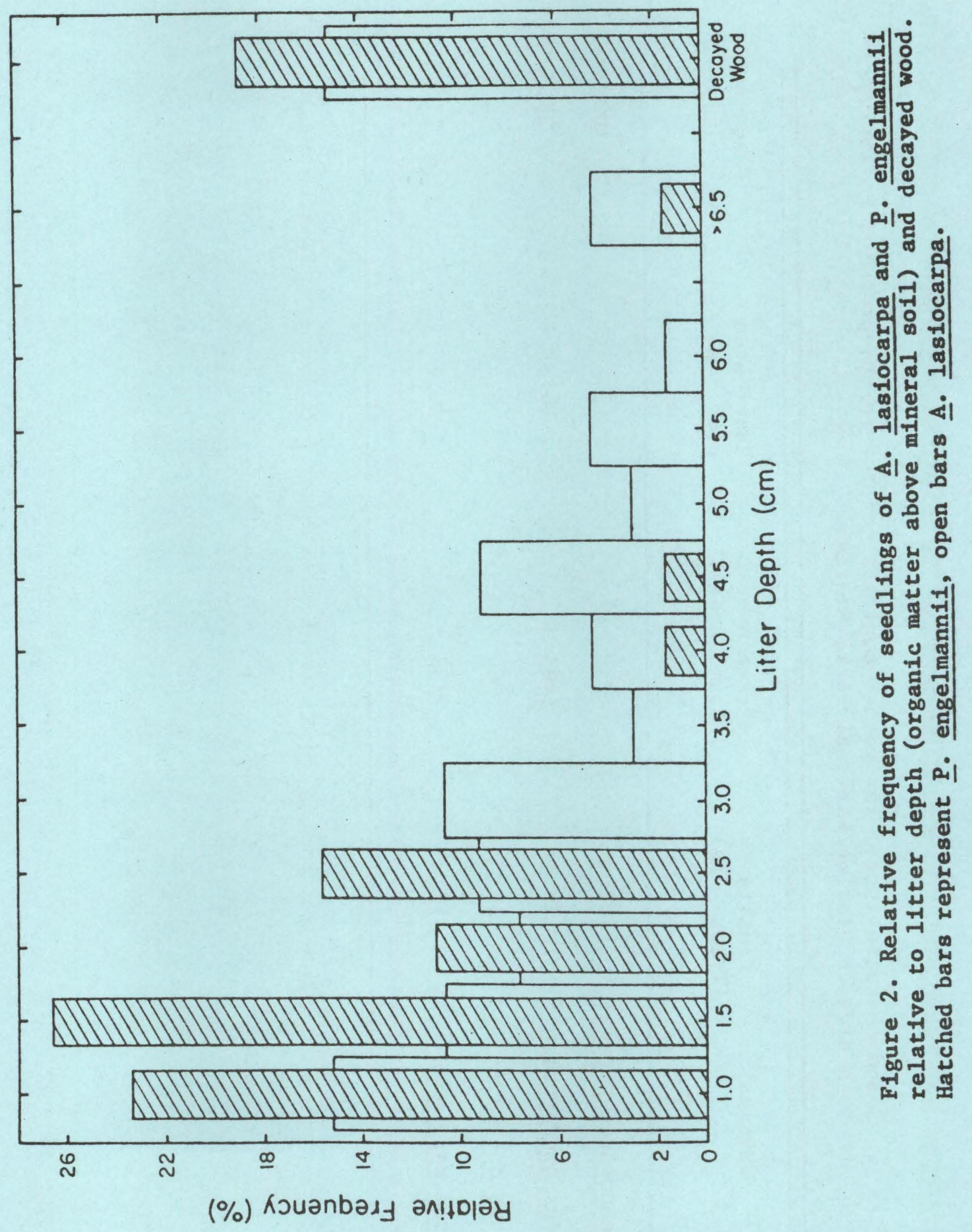




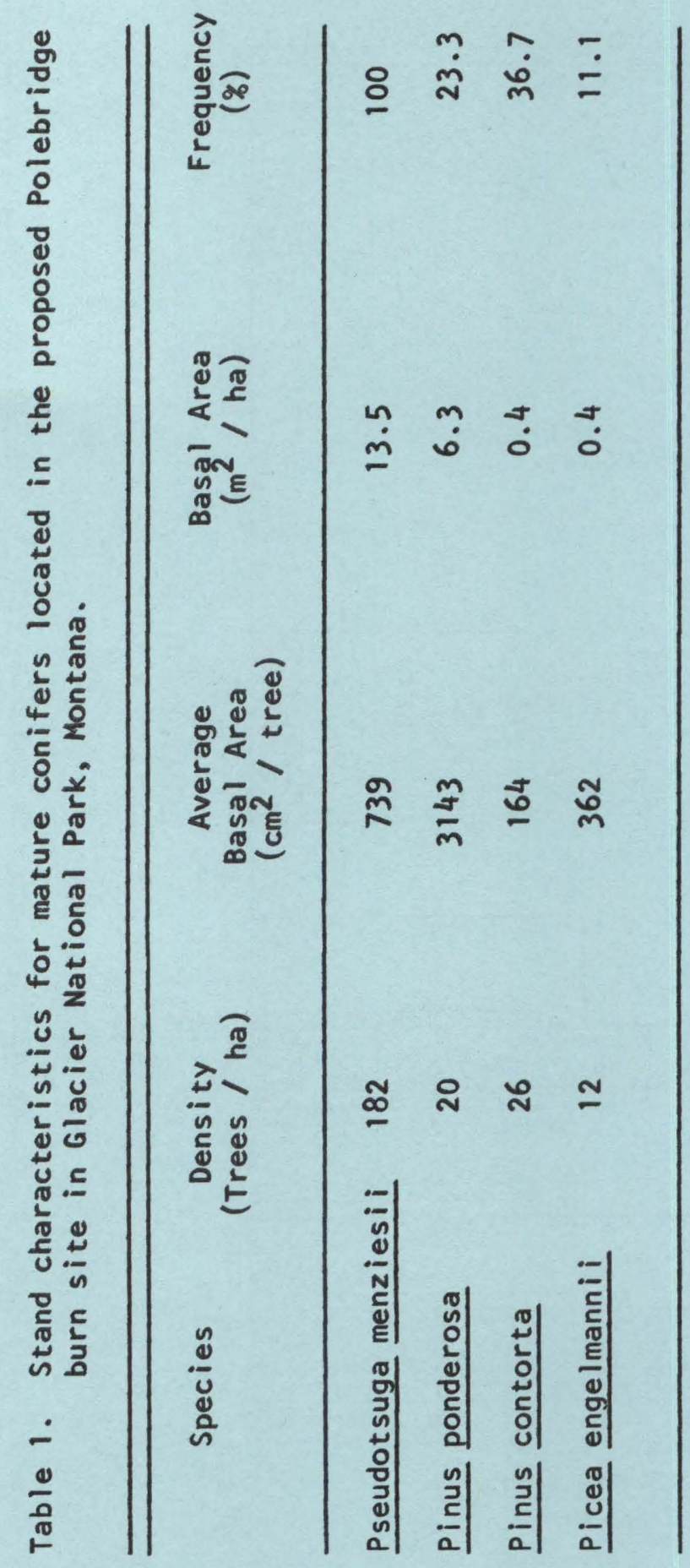


at this site:

\section{Conclusions}

It appears that species differences in seedling growth (root penetration) between Engelmann spruce and subalpine fir may be more important than differences in shade tolerance in determining seedling establishment success. Thus, reduction in litter layer thickness by burning may benefit seedling establishment of Engelmann spruce more than subalpine fir and be more important than an increase in solar radiation at a site following a fire. Other factors influencing the seedling establishment of these and other conifers in GNP need to be evaluated to allow prediction of seedling establishment patterns and plant community composition following a prescribed burn.

\section{Literature Cited}

Ahlgren, I. F. and C. E. Ahlgren. 1960. Ecological effects of forest fires. Bot. Rev. 26: 483-533.

Alexander, R. P. 1974. Silviculture of subalpine forests in the central and southern Rocky Mountains: The status of our knowledge. U.S. Dept. Agric. For. Serv. Res. Pap. RM-121. 88 pp.

Cottam, G. and J. T. Curtis. 1956. The use of distance measures in phytosociological sampling. Ecology 37: 451-460.

Day, R. J. 1972. Stand structure, succession, and use of southern Alberta's Rocky Mountain forest. Ecology 53: 472-478.

Habeck, J. R. 1970. Fire ecology investigations in Glacier National Park. Botany Dept. Univ. of Montana. $80 \mathrm{pp}$.

Oosting, H. J. and J. F. Reed. 1952. Virgin spruce-fir of the Medicine Bow Mountains, Wyoming. Ecol. Monogr. 22: 69-91.

Smith, D. W. and T. D. James. 1977. Characteristics of prescribed burns and resultant short-term environmental changes in Populus tremuloides woodland in southern Ontario. Can. J. Bot. 56: 17821791 .

Smith, J. H. G. and M. B. Clark. 1960. Growth and survival of Engelmann spruce and alpine fir on seed spots at Bolean Lake, B.C., 1954-59. For. Chron. 36: 46-49.

Sweeney, J. R. and H. H. Biswell. 1961. Quantitative studies of the removal of litter and duff by fire under controlled conditions. Ecology 42: 572-575. 